\title{
Hydrodynamic performance of psammosteids: New insights from computational fluid dynamics simulations
}

\author{
Marek Dec \\ Acta Palaeontologica Polonica 64 (4), 2019: 679-684 doi:https://doi.org/10.4202/app.00623.2019
}

The shape of dermal armor protecting the body in the Paleozoic agnathans such as the Heterostaci has an important hydrodynamic role in providing lift or drag force generation. Here, by performing computational fluid dynamics simulations (CFD), the measurements of hydrodynamic lift/drag force and lift or drag coefficients were taken for two psammosteids Guerichosteus and Tartuosteus with reference to the pteraspid Errivaspis . This study shows the substantially higher values of the lift coefficient and lift-to-drag ratio for the psammosteids Guerichosteus and Tartuosteus compared with Errivaspis. The tendencies in the evolution of dermal exoskeleton, especially the widening of the branchial plates of psammosteids was directed towards the increased generation of lift force to provide efficient cruising.

Key words: Agnatha, dermal armor, hydrodynamic, Paleozoic.

Marek Dec [mdec@wp.pl], Institute of Palaeobiology, Polish Academy of Sciences, Twarda 51/55, 00-818 Warszawa, Poland.

This is an open-access article distributed under the terms of the Creative Commons Attribution License (for details please see creativecommons.org), which permits unrestricted use, distribution, and reproduction in any medium, provided the original author and source are credited. 